\title{
Selective hippocampal lesions in rats do not affect retrieval processes promoted by prior cuing with the conditioned stimulus or the context
}

\author{
PASCALE GISQUET-VERRIER \\ Laboratoire de Neurobiologie de l'Apprentissage et de la Mémoire, Orsay, France \\ and \\ FRANÇOISE SCHENK \\ Institut de Physiologie, Lausanne, Switzerland
}

\begin{abstract}
Following partial training in an avoidance brightness discrimination task in a Y-maze, the retention performance can be enhanced by a pretest exposure to various training features (prior cuing). The effectiveness of these cues may vary as a function of the length of the retention interval. These results demonstrate that prior cuing promotes the retrieval of the memory trace and that the memory trace is submitted to a long-lasting time-dependent reorganization. The present experiments were designed to examine the involvement of the hippocampal formation in retrieval processes promoted by prior cuing. Rats with bilateral ibotenic acid hippocampal lesions and sham-operated rats were postoperatively trained in the avoidance brightness discrimination task. Retrieval processes promoted by prior cuing were not affected by hippocampal lesions: After a 1-day training-to-test interval (TTI), the rats in both conditions demonstrated a dramatic improvement of retention performance following a pretest exposure to the conditioned stimulus (CS; Experiment 1). After a 21-day TTI, exposure to the CS was no longer effective, and a pretest exposure to the experimental context enhanced performance (Experiment 2). In contrast, when the lesioned rats were tested in a radial arm maze task, they showed severely impaired performance, demonstrating the effectiveness of the hippocampal lesions on behavior. These results demonstrated that damage to the hippocampus does not disrupt the promotion of retrieval processes by prior cuing. In particular, the lesions did not prevent the rats from being able to relate the CS and the experimental context to the initial training episode. The fact that the hippocampal lesions also did not disrupt time-dependent changes in the effectiveness of certain retrieval cues suggests that this structure is not involved in the long-term maturation processes evidenced by prior cuing.
\end{abstract}

Pretest exposure to some components of a learning episode is known to enhance subsequent retention performance. Such a phenomenon has been demonstrated following (1) a performance decrement resulting from experimentally induced amnesia (Koppenaal, Jagoda, \& Cruce, 1967; Miller \& Springer, 1972; Sara, 1973), (2) a spontaneous decrease in performance, such as the Kamin effect (Gisquet-Verrier \& Alexinsky, 1990; Klein \& Spear, 1970), or (3) long-term forgetting (Deweer, Sara, \& Hars, 1980; Gisquet-Verrier \& Alexinsky, 1986; Gisquet-Verrier, Dekeyne, \& Alexinsky, 1989). A similar enhancement of subsequent retention performance has also been observed in the absence of any performance disruption (Gisquet-Verrier \& Alexinsky, 1990).

This research was supported by European Science Foundation ETP Twinning Grant 9040 and by Swiss National Foundation Grant 3130068.90. The authors wish to thank Sabrina Davis for her helpful assistance in correcting the text. Correspondence concerning this article should be addressed to P. Gisquet-Verrier, Laboratoire de Neurobiologie de l'Apprentissage et de la Mémoire, NAM, URA CNRS 1491, Bât. 446, Université Paris-Sud, 91405 Orsay Cedex, France.
This effect is a specific phenomenon: in order to be effective, the cue has to be related to a training episode (Gisquet-Verrier \& Alexinsky, 1987; Springer \& Miller, 1972). It is highly reliable and has been observed in many different species, such as rats, mice, pigeons, and humans.

Prior cuing, which typically involves the presentation of some aspects of the conditioning episode and results in a better expression of learning, is thought to induce memory reactivation. Indeed, several studies have demonstrated that exposing an animal to some specific training information, such as the unconditioned stimulus (UCS), reinduces a susceptibility of the related memory trace to an experimentally induced amnesia (Howard, Glendenning, \& Meyer, 1974; Misanin, Miller, \& Lewis, 1968) or to the action of promnesic agents (De Vietti, Conger, \& Kirkpatrick, 1977; Gordon \& Spear, 1973), even long after training. These studies suggest that prior cuing reinstates the memory trace to a state that is similar to that at the end of training. It is thus likely that there are (at least) two possible states for a memory: an active state, which corresponds to the 
same type of neuronal activity that occurs during the learning episode (Lewis, 1979) and a passive state, which corresponds to the storage form and involves chemical and long-lasting structural alterations at the synaptic level. Exposing the subject to some training events by prior cuing may result in transforming a passive memory trace into an active one. The general view holds that the presentation of the cue activates the corresponding internal representation(s) or memory attribute(s). This reactivation may trigger reactivation of other related attributes and ultimately lead to the whole memory trace reactivation (Miller, Kasprow, \& Schatman, 1986; Spear, 1978).

In a previous study, the effects of nine different priorcuing treatments were investigated after three particular retention intervals, following partial acquisition of an avoidance brightness discrimination task (GisquetVerrier et al., 1989). This study revealed two major findings. First, pretest exposure to various components of the original training situation promoted reactivation of the memory trace after a particular retention interval. Second, the effectiveness of some of the cuing treatments was specifically dependent on the length of the retention interval. Exposure to simple cues, such as the conditioned stimulus (CS), was particularly effective following short retention intervals ( $1 \mathrm{~h}$ to $1 \mathrm{day}$ ), but exposure to complex cues, such as the experimental context, was particularly effective a long time after training (21 days). These results confirm hypotheses about the multidimensional nature of the memory trace (Bower, 1967; Underwood, 1969) and provide strong arguments for its long-lasting maturation process. The fact that the effectiveness of some retrieval cues varies during the retention interval suggests that the memory trace is modified during the retention interval and that a maturation or consolidation process takes place during the first weeks following initial training.

The fact that the hippocampus might be involved in the maturation of the memory trace is supported by recent findings showing that hippocampal lesions in rodents and monkeys was accompanied by a temporally graded amnesia, in which information that had been stored a long time before the lesion was remembered better than recent information, stored only shortly before the lesion (Cho, Beracochea, \& Jaffard, 1993; ZolaMorgan \& Squire, 1990). This suggests that destruction of the hippocampus interferes with these long-term maturation processes and reduces the postoperative retention of material acquired shortly before the lesion. If the shift in effectiveness of some retrieval cues reflects a maturation process that is the same as that evidenced by temporally graded retrograde amnesia, then destruction of the hippocampus might also prevent the long-term processes underlying a change in effectiveness of the retrieval cues. According to this position, one might hypothesize that rats with hippocampal lesions would not demonstrate a normal alteration of the sensitivity to prior cuing at different retention intervals, namely, $24 \mathrm{~h}$ and 21 days posttraining.

The hippocampal formation, generally considered as a determinant structure for learning and memory processes, has also been proposed to be involved in memory-retrieval operations (Warrington \& Weiskrantz, 1974; Winocur \& Olds, 1978). Hirsh (1974) maintains that the hippocampal formation is essential for the process of contextual retrieval-that is, as a part of a system that is responsible for determining which information is to be transferred from storage to the performance system. Teyler and DiScenna (1986) proposed that the memory trace is encoded as a file entry, or index, within the hippocampal formation. According to these authors, as well as Moscovitch (1992), a memory trace must be reactivated via the hippocampal component in order to allow a conscious recollection of an event. However, the hippocampus is not necessary for the recollection of all stored items, and it has recently been suggested that the hippocampal formation could play a determinant role by providing the neural basis for the acquisition, storage, and retrieval of configural associations among events (Sutherland \& Rudy, 1989). In our experimental situation, complex cues involving relationships between the training features (such as the experimental context) are critically effective for a long time after training, whereas simple cues (the CS) are particularly important shortly after training. According to Sutherland and Rudy, the hippocampus would be particularly involved in the retrieval processes, long after initial training.

The present series of experiments was aimed at analyzing whether and how the hippocampus might be involved in the retrieval processes promoted by an exposure to retrieval cues. Studying the effects of hippocampal lesions on retrieval processes with an avoidance brightness discrimination seems a well-adapted task because, according to the literature, the acquisition of such a task is not affected by hippocampal lesions (Olton, 1973; Silveria \& Kimble, 1968).

In the present experiments, rats were given selective ibotenic acid lesions to the hippocampus before initial acquisition, and their performance on retention of the avoidance brightness discrimination task was tested. The main purpose was to investigate the involvement of the hippocampus in the retrieval processes triggered by a pretest exposure to some learning events at short and long intervals after initial training. More specifically, the effects of the exposure to a simple cue (the CS) were investigated after 1 day and after 21 days following initial training, and the effects of the exposure to a complex cue (experimental context) were tested after the longer interval.

Following each experimental study, rats were trained in a radial maze in order to assess the behavioral validity of the lesions in a task known to be very sensitive to a disruption of the hippocampal formation. 


\section{GENERAL METHOD}

\section{Subjects}

The subjects were naive male Sprague-Dawley rats obtained from the Iffa-Credo breeding center. They were 50-57 days old and weighed $250 \mathrm{~g}$ at their arrival in the laboratory. They were housed individually in wire-mesh cages and maintained on a 12:12-h light:dark cycle. They had free access to food and water throughout the experiment, except when noted in the behavioral protocol. All the rats were regularly handled before the start of behavioral testing in order to familiarize them with the experimenters.

\section{Surgery}

The rats were anesthetized with pentobarbital $(50 \mathrm{mg} / \mathrm{kg})$ and placed in a Kopf stereotaxic frame. Bilateral lesions of the hippocampus were made by injections of ibotenic acid (Sigma Chemical Co.) dissolved in phosphate buffered saline (final pH 7.4) at a concentration of $10 \mathrm{mg} / \mathrm{ml}$. Injections were made with a microinjector equipped with a micropipette and mounted on the stereotaxic frame. The stereotaxic coordinates that were used (adapted from Jarrard, 1989) are given in Table 1. Twenty-six injections of $0.10 \mu \mathrm{l}$ or $0.05 \mu \mathrm{l}$ were made manually over $1 \mathrm{~min}$ at each site, and the pipette was left in place an additional 2 min to prevent spreading up the track. Since the micropipette was very thin $(0.2 \mathrm{~mm}$ diameter $)$, and since its insertion is not known to lead to cortical damage in hippocampal rats, the sham-operated rats were subjected to the same surgical procedure, with incision of the dura but no penetration of the micropipette. Ten to 14 days were allowed for postoperative recovery.

\section{Apparatus \\ Y-maze. Training and testing were carried out in a fully auto- mated black perspex Y-maze, with arms that were $13 \mathrm{~cm}$ wide $X$ $60 \mathrm{~cm}$ long $\times 38 \mathrm{~cm}$ high and a $25-\mathrm{cm}$ equilateral triangular choice area. A 40-W lamp was located at the end of each arm. The floor consisted of 3 -mm-diam. grids, spaced $9 \mathrm{~mm}$ apart. A shock generator (Campden, Model 521S), set to deliver scrambled shock, provided the incentive for learning. Photocells placed $1 \mathrm{~cm}$ (proximal), $11 \mathrm{~cm}$ (medial), and $30 \mathrm{~cm}$ (distal) from the entrance of each arm were connected to a Hewlett-Packard vectra micro- processor, which controlled the light sequence and the length of the intertrial interval and recorded latencies and the sequence of}

Table 1

Coordinates for Hippocampal Lesions

\begin{tabular}{cll}
\hline Anterior & Lateral & Ventral \\
\hline 2,4 & $+/-1$ & $-3,4$ \\
3 & $+/-1,4$ & $-2,6^{*}$ \\
& $+/-2,7$ & $-3,4^{*}$ \\
4 & $+/-2,3$ & -3 \\
& & $-2,3^{*}$ \\
& $+/-3,2$ & $-3,3^{*}$ \\
4,9 & $+/-3,5$ & -3 \\
& & $-3,5^{*}$ \\
5,7 & $+/-4,1$ & -7 \\
& $+/-5,1$ & $-3,8$ \\
& & -4 \\
& & $-4,9$ \\
& & $-5,8$
\end{tabular}

Note-All coordinates (in millimeters) are given with reference to stereotaxic zero according to Paxinos and Watson's (1986) rat brain atlas. The volume of ibotenic acid injected was $0.10 \mu \mathrm{l}$ at all sites, except for coordinates marked with an asterisk $\left({ }^{*}\right)$, in which the amount was $0.05 \mu \mathrm{l}$. visited arms. The maze was located in a darkened room that was adjacent to the colony room.

Cuing. Cuing treatment was delivered in either a cuing box or a wire-mesh cage that was similar to the rats' home cages. The cuing box, which differed from the experimental apparatus in size $(23 \times 23 \times 36 \mathrm{~cm})$ and color (beige), was covered with a removable ceiling that was equipped with a $40-W$ lamp.

Radial maze. The radial maze was a wooden maze, painted gray. It consisted of eight identical paths $(60 \times 12 \mathrm{~cm})$ radiating from an octogonal starting platform. Each arm was fitted with edges and an opaque plastic food cup at the distal end. Condensed milk, placed in the food cup, served as the reinforcer during training. The maze was elevated to $70 \mathrm{~cm}$ above the floor and was maintained in a constant orientation during learning. The radial maze was placed in a room that had several distinctive cues (two doors, a chair with the experimenter, and a lamp that was located just above the central platform).

\section{Procedure}

Avoidance discrimination in the Y-maze. The general design of this series of experiments follows.

Pretraining. On Day 1, groups of 6 rats were given $15 \mathrm{~min}$ of free exploration in the entirely lighted maze. On Day 2, each rat was allowed to explore the lighted maze for $5 \mathrm{~min}$.

Training. Training began on the following day. All the rats were given 15 trials according to the following procedure. Each rat was placed in the lighted start arm of the Y-maze for $20 \mathrm{sec}$. The door closing the start arm (used only for the first trial) was then opened, the light was turned off, and another arm, designated as the "safe" arm, was lighted. Five seconds later, an electric shock was applied to the grid floor in the whole maze, except in the terminal $30 \mathrm{~cm}$ of the safe arm. The rat remained in the safe compartment for a 20 -sec intertrial interval, during which an exit from the safe alley led to shock. The goal alley on any given trial served as the start alley for the next trial. During the first 5 trials, the intensity of the electric shock was adapted for each animal just below the vocalization threshold; this corresponded to the minimal level for eliciting a rapid response (between .3 and $.5 \mathrm{~mA}$ ). The rat had to run to the safe arm in order to escape or avoid the footshock. The sequence of correct right and left turns in the Y-maze was as follows: L-L-R-L-R-R-L-R-R-L-R-L-L-R-R.

After completion of the 15 training trials, the rats were removed from the maze and returned to their home cages, where they remained until their training-to-test-interval (TTI; 1 day in Experiment 1 and 21 days in Experiment 2). Sham and lesioned rats were divided into matched groups on the basis of their performance: response latencies, number of errors, and number of avoidance responses that were obtained during the entire training session (i.e., the three blocks of 5 trials).

Behavioral measures. The time that elapsed between the illumination of a new goal arm and the rat's crossing the proximal photobeam of the initial arm was defined as the start latency. The time that it took the rat to cross the distal photobeam of the new goal arm was defined as the response latency. When the rat crossed the medial photobeam of an arm, the arm was considered to have been visited. An incorrect response was scored when the rat entered one of the shocked alleys, before escaping to the safe alley. The rats that failed to respond within $60 \mathrm{sec}$ were manually pushed into the safe arm, and a response latency of $60 \mathrm{sec}$ was scored. The rats that responded with mean response latencies greater than $30 \mathrm{sec}$ during the last five training trials were discarded.

Two categories of avoidance responses were noted. A start latency less than $5 \mathrm{sec}$ corresponded to an exit from the initial arm during the CS-UCS interval. Such a response, emitted before the onset of the UCS and equivalent to an avoidance response in a shuttlebox apparatus, was considered as an attempt to avoid and 
was scored as 1 . Reaching the goalbox in less than $5 \mathrm{sec}$ permitted avoidance of the shock and was scored as 2 .

The response latencies (logarithmic transformation), the number of errors, and the avoidance score were pooled in blocks of five trials for training and testing. The number of errors was very low at the end of training, so this measure was not useful during retention because of a floor effect. Avoidance scores were preferred to response latencies as an index of learning the task, because starting to move before the onset of the UCS seemed to be more appropriate as an adaptive response than moving faster. Furthermore, a few escape responses with long latencies, due to emotional reactiveness to shock (freezing), had a greater effect on the mean latencies than did several avoidance responses emitted within a response time close to $5 \mathrm{sec}$. Therefore, savings in avoidance, expressed as the difference between the mean score of the first five testing trials and that of the last five training trials, served as a measure of retention (for more details, see Gisquet-Verrier \& Alexinsky, 1988).

Cuing. Before the testing session, the rats cued with the conditioned stimulus, Groups Box + Light (BL), were placed in the cuing box, which was set in a room situated between the colony room and the experimental room. The rats were in the box for a 2.5-min period and were exposed to a series of five 2-sec flashes presented every $28 \mathrm{sec}$-similar (except for duration) to those used previously as the conditioned stimulus. The rats cued with the experimental context, Group CTXT, were placed for $2.5 \mathrm{~min}$ in the wire-mesh cage, which was located in the experimental room and had an external environment identical to the one used for initial training. At the end of the cuing treatment, the rats were returned to their home cages for a 5-min period.

Testing. At the end of this period for the cued rats, or at the end of the retention interval for the noncued rats, they were removed from their home cages, carried to the experimental room, and placed directly into the start arm of the Y-maze. Twenty seconds later, the starting door was opened and the rats were retrained for 25 trials in conditions that were the same as those for the initial training. The lighted arm was positioned according to the following sequence: L-R-R-R-L-L-R-L-L-L-R-L-L-R-L-R-R-R-L-L-RR-L-R-R.

Statistical analyses. Contrast analyses of variance (ANOVAs; Rouanet, Bernard, \& Leroux, 1990) were performed on the data.

The experiments were run over several consecutive days. Every day, rats from each of the experimental conditions were placed in the pretraining phase. Over subsequent days, they were subjected to the entire procedure until all the experimental groups were tested.

Radial maze training. One month (first experiment) or 4 months (second experiment) after the lesions were made, the rats were placed on a food-deprivation schedule. The daily food ration was adjusted so that the rats were reduced to $85 \%$ of their ad-lib weights. The rats were habituated to drink condensed milk in their home cages for 2 days. On the day of pretraining, each rat was placed in the center of the maze, and a drop of condensed milk was placed into each food cup. The rats were removed from the maze after obtaining all food rewards or after a $10-\mathrm{min}$ period. The training procedure started on the following day. Lesioned and sham rats were tested on one trial a day for 6 days. For each trial, a rat was placed on the central platform and was left in the maze until it visited each of the eight arms. The total number of reentries before visiting the eight arms was recorded for each trial.

Histology. After completion of the behavioral studies, the rats were given an overdose of sodium pentobarbital $(120 \mathrm{mg} / \mathrm{kg})$ and were perfused with saline, which was followed by $10 \%$ buffered formalin. Their brains were postfixed in buffered formalin and then in a $30 \%$ sucrose-formalin solution for $48 \mathrm{~h}$. Then they were frozen and cut on a microtome into $60-\mu \mathrm{m}$ sections. Every fourth section was taken, mounted on a gelatin-coated slide, and stained with cresyl violet.

\section{EXPERIMENT 1}

Rats that were submitted to partial acquisition of a brightness avoidance discrimination task demonstrated a dramatic enhancement of retention performance following a pretest exposure to the CS when it was delivered $1 \mathrm{~h}$ to 1 day after the initial acquisition (Gisquet-Verrier, 1992; Gisquet-Verrier \& Alexinsky, 1990; Gisquet-Verrier et al., 1989). In the present Experiment 1, we used the same experimental paradigm for rats with lesions to the hippocampus and sham-operated rats, in order to determine the role of the hippocampus in the retrieval processes promoted by prior cuing.

Additionally, in order to provide a behavioral assay of the hippocampal lesion, all the rats were trained in a radial maze task, which is known to be very sensitive to hippocampal damage.

\section{Method}

Subjects and surgery. Forty-seven male Sprague-Dawley rats served as subjects in the first experiment. One week after their arrival, they were submitted to the surgical procedure. Nineteen of the rats received bilateral lesions of the hippocampus, which were made by injection of ibotenic acid (as described previously). Twenty-eight rats were given sham operations. The rats were allowed 2 weeks of postoperative recovery before we started the experiment.

Histology. The nature and extent of the brain damage resulting from injections of ibotenic acid was determined by using cell stains. Frontal and horizontal sections $(60 \mu \mathrm{m})$ throughout the full anteroposterior and dorsoventral extent of the hippocampal formation were examined. Figure 1 shows cresyl-violet-stained sections from two of the lesioned rats and represents examples of the less extensive, accepted lesions. To be included in the group, it was necessary for almost all of the dorsal hippocampus CA1-CA4 pyramidal cells and most of the granule cells to be damaged or completely removed with minimal involvement of the adjacent areas. Occasional residual fragments in the dorsal hippocampus, such as that evident on the micrography (Figure 1), were examined to assess damage to cell bodies. In the accepted cases, the neurons in the fragments were mostly picnotic, which suggests that they did not contribute to a normal hippocampal function. Damage was complete in the dorsal hippocampus in all of the 15 accepted subjects. Residual fragments of the ventral hippocampus were preserved in some of these cases. The extent of damage to the subiculum was variable; it did not lead to exclusion.

Procedure. Following pretraining, the rats were trained on 15 massed trials in the brightness discrimination avoidance task. At the end of training, 4 of the sham-operated rats and 2 of the lesioned rats were discarded because of their extended mean response latencies during initial training. Sham (S) and hippocampus-lesioned (H) rats were then divided into two groups on the basis of their training performance according to a 2 (sham or lesioned) $\times 2$ (cued or noncued) factorial design. After a 1-day TTI, the rats were either cued or directly placed into the maze. The cued rats (Group SBL, $n=12$ and Group H-BL, $n=7$ ) were exposed to the CS that was delivered in the cuing box, while the noncued rats (Group S-NC, $n=12$ and Group H-NC, $n=6$ ) remained in their cages. All of the rats were then retrained for 25 trials under conditions that were the same as those used in the initial training period.

\section{Results}

Acquisition of the Y-maze task. As is depicted in Figure 2, the hippocampus-lesioned rats' score for vis- 


\section{Horizontal sections $(\beta-3.6 ; \beta-5.6)$}
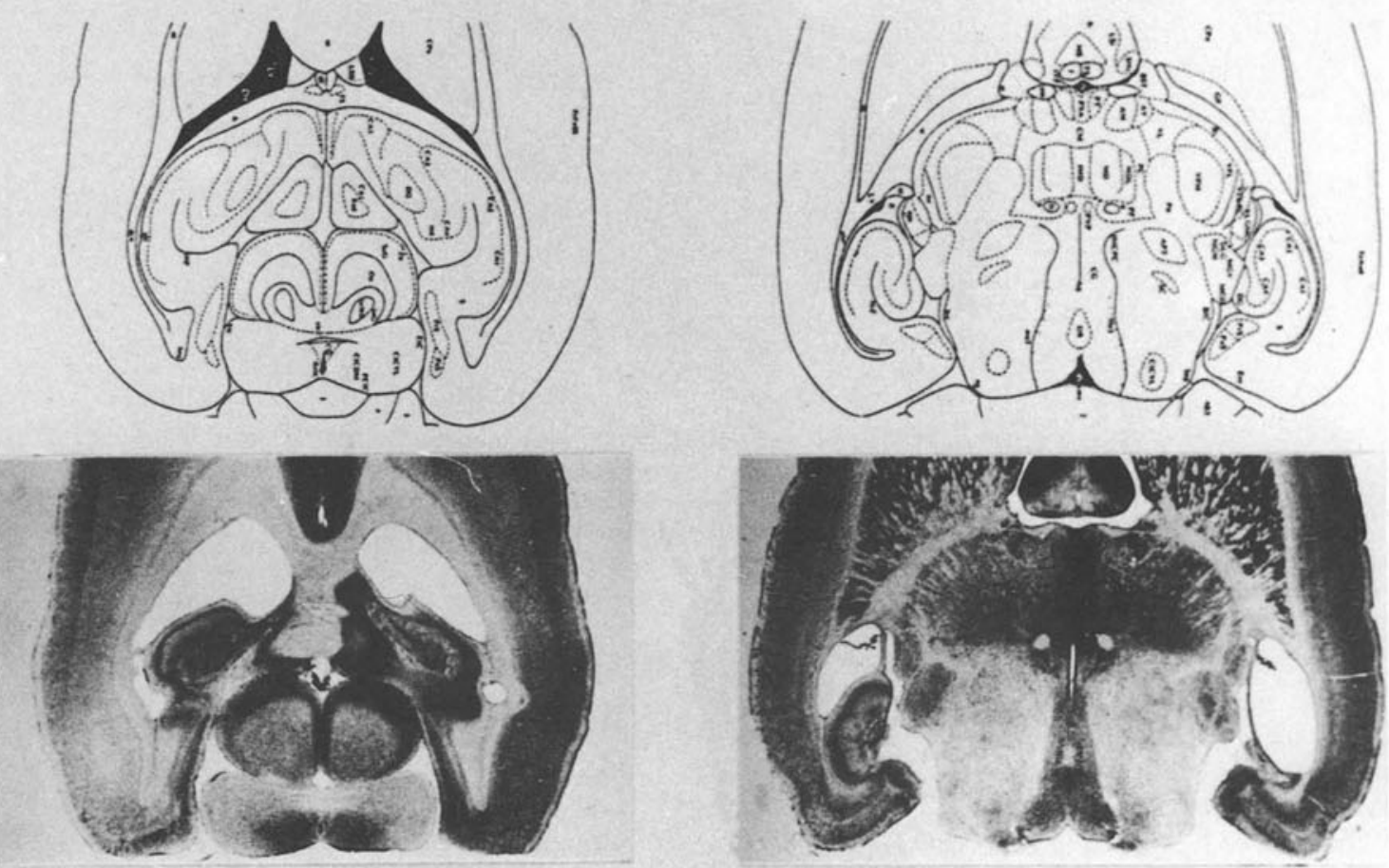

\section{Frontal sections $(\beta-3.8 ; \beta-5.8)$}
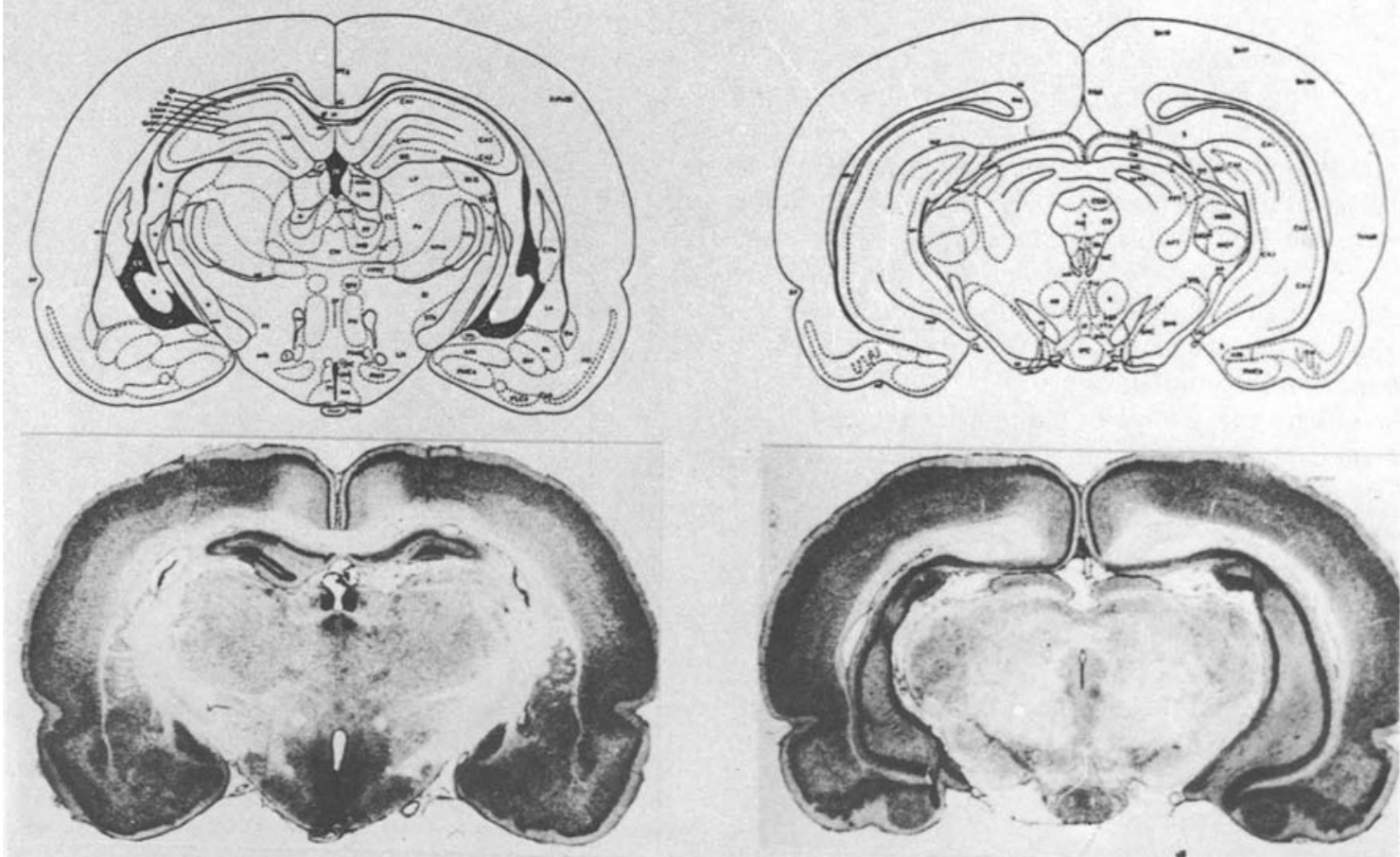

Figure 1. A representation of the less extensive, accepted hippocampal lesions (see text for details). 


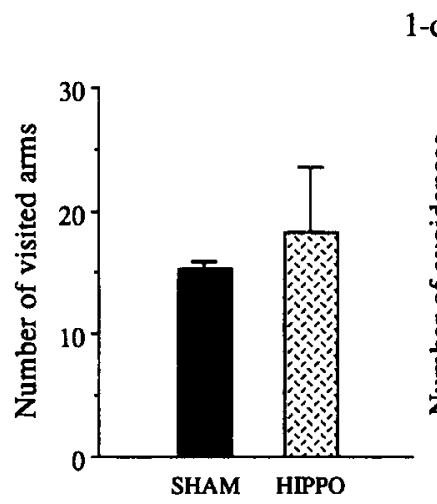

PRETRAINING

\section{1-day TTI}

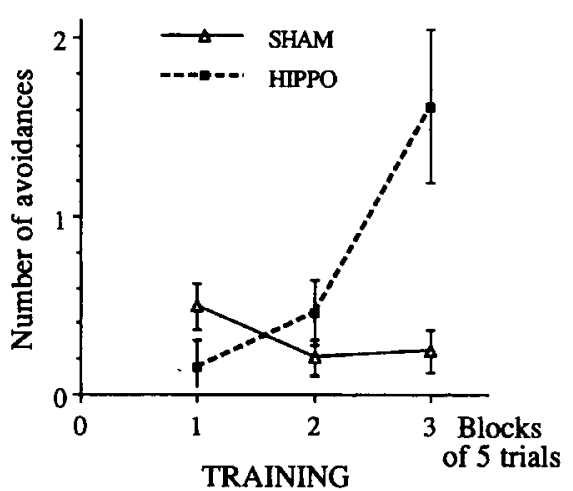

Figure 2. One-day training-to-test interval (TTI). Mean number $( \pm S E M)$ of arms visited for sham-operated (SHAM) and hippocampus-lesioned (HIPPO) rats during pretraining (left panel), and number of avoidance responses ( $\pm S E M$ ) during initial training (right panel). HIPPO rats visited significantly more arms during pretraining and performed more avoidance responses than did SHAM rats.

ited arms was significantly higher than that for the sham rats, during the 5 -min pretraining period $[F(1,33)=$ $6.24, p<.025]$.

During training, a two-way ANOVA (lesion condition $X$ trial block) indicated a significant effect of trial block for each variable [response latencies, $F(2,66)=35.66$, $p<.001$; errors, $F(2,66)=10.31, p<.001$; avoidance responses, $F(2,66)=3.36, p<.05$ ], demonstrating a significant acquisition. A significant effect of the lesion condition was also obtained; the lesioned rats demonstrated shorter response latencies $[F(1,33)=9.91, p<$ $.005]$ and a higher score of avoidance response $[F(1,33)=$ $6.66, p<.025]$ than the sham-operated rats. No difference was obtained on the number of errors $(F<1)$.

Retraining. No effect of the lesion condition was found when performance at the end of training was compared with performance at the beginning of retraining, regardless of the measure $\left(F_{\mathrm{S}}<1\right)$. However, during retraining, the hippocampus-lesioned rats still demonstrated shorter response latencies $[F(1,16)=5, p<$ $.05]$ and a higher number of avoidance responses than controls did $[F(1,16)=10.77, p<.005]$. There was no difference on the number of errors $(F<1)$.

The effectiveness of prior cuing after a 1-day TTI is illustrated in Figure 3. Within-group comparisons on the number of avoidances indicated a significant improvement of performance between the end of training and the beginning of retraining for both of the cued groups [S-BL, $F(1,11)=14, p<.005 ; \mathrm{H}-\mathrm{BL}, F(1,6)=16.62$, $p<.01]$. There was no improvement of performance in the two noncued groups $(F \mathrm{~s}<1)$.

A two-way ANOVA (lesion condition $\times$ cuing condition) performed on the savings in avoidance indicated no effect of the lesion condition $(F<1)$, a significant effect of the cuing condition $[F(1,33)=14.22, p<.001]$, and no significant interaction between the lesion and cuing conditions $(F<1)$. No difference was obtained between the sham and hippocampus-lesioned rats that were submitted to the same cuing conditions $(F \mathrm{~s}<1)$.

Paired comparisons of savings in avoidance performed between the noncued and cued rats indicated that pretest exposure to the CS induced a significant improvement of the retention performance in the sham condition $[F(1,22)=9.85, p<.005]$ as well as in the hippocampal condition $[F(1,11)=4.87, p<.05]$.

Acquisition of the radial maze task. One week following the completion of the behavioral test in the Y-maze (i.e., approximately 1 month following the surgery), all the rats were tested on the radial maze test. The number of errors that were performed by the rats before visiting each of the eight arms of the radial maze are presented

\section{1-day TTI}
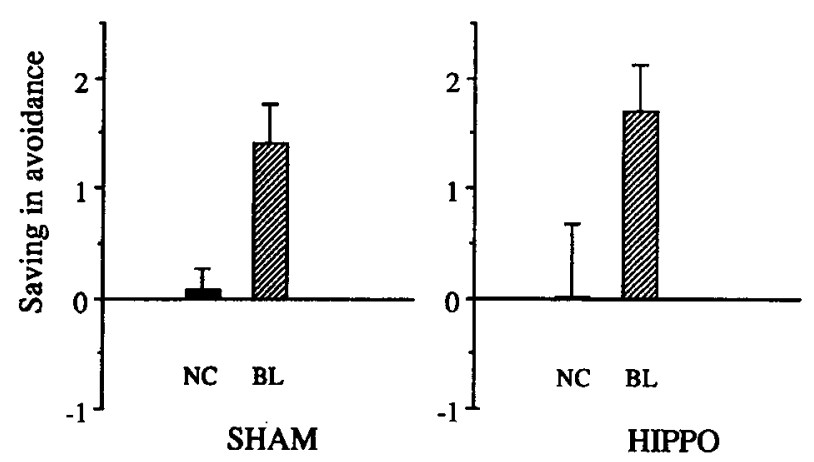

Figure 3. One-day training-to-test interval (TTI). Mean score ( $\pm S E M$ ) of savings in avoidance (difference between the number of avoidance responses obtained during the first five testing trials and the last five testing trials) obtained for sham-operated (SHAM) and hippocampus-lesioned (HIPPO) rats. NC, noncued; BL, cued with the CS. Cued rats (SHAM and HIPPO) demonstrated a higher saving in avoidance than did the corresponding noncued rats. 


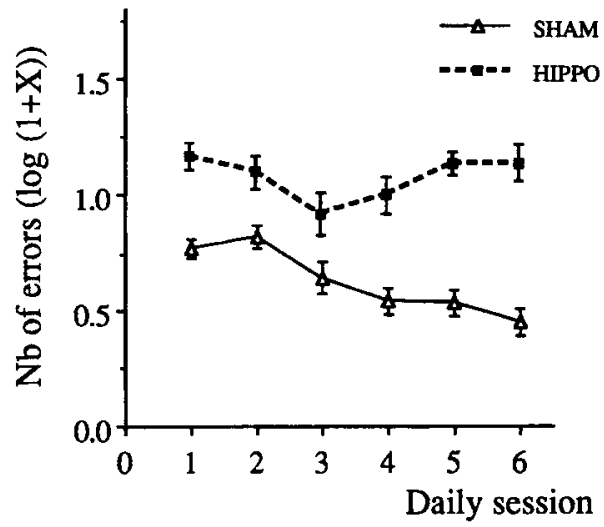

Figure 4. Mean number of errors $[\log (x+1) \pm S E M]$ obtained for sham-operated (SHAM) and hippocampus-lesioned (HIPPO) rats for visiting eight different arms in the radial maze. HIPPO rats demonstrated a significantly higher number of errors than did SHAM rats.

in Figure 4. Statistical analysis of the data revealed a significant main effect of the lesion condition; the hippocampuslesioned rats showed a higher score of errors throughout training than did nonlesioned rats $[F(1,42)=99.95, p<$ $.001]$. The sham-operated rats demonstrated a significant effect of repetition among the training sessions $[F(5,135)=7.023, p<.001]$. The effect of repetition was not significant for the hippocampus-lesioned rats $[F(5,75)$ $=2.28, p<.1]$.

\section{Discussion}

The hippocampal lesions did not disrupt acquisition or retention (after a 1-day TTI) of an avoidance brightness discrimination task. In fact, the rats with damage to the hippocampus were more active during pretraining and made higher avoidance scores than the control rats, but they showed similar discrimination performance. These results confirmed those of previous studies, which have indicated that the acquisition of this type of task does not require the participation of the hippocampal formation.

As expected, a pretest exposure to the CS largely improved the subsequent retention performance when it was delivered 1 day following initial training (GisquetVerrier \& Alexinsky, 1990; Gisquet-Verrier et al., 1989). This effect was identical in the hippocampus-lesioned and the intact rats. This absence of deficit cannot be explained by an incomplete lesion, because all the lesioned rats were clearly impaired during acquisition of the radial maze task. One can thus assume that the hippocampus is not involved in the retrieval processes that are triggered by prior cuing with the light stimulus shortly after training.

\section{EXPERIMENT 2}

The first experiment demonstrated that the hippocampal formation is not critically involved in retrieval processes that are promoted by prior cuing shortly after training when simple cues are effective. In the second experiment, we investigated the possible involvement of the hippocampus in the retrieval processes following a longer posttraining interval, in which simple cues are no longer effective and complex cues are the most effective in enhancing the subsequent retention performance (Gisquet-Verrier et al., 1989). Hence, this experiment was a further investigation of the possible involvement of the hippocampus in the maturation of the memory trace, evidenced by the shift in effectiveness of some retrieval cues that occurs over time.

In this experiment, sham-operated and hippocampuslesioned rats were trained to the avoidance brightness discrimination task, as in the first experiment. After a 21-day retention interval, they were tested following no cue presentation, an exposure to a simple cue (CS), or after exposure to a complex cue (the experimental context).

As in the first experiment, the rats were then trained in a radial maze task in order to provide a behavioral assay of the validity of the hippocampal lesions.

\section{Method}

Subjects and surgery. Sixty-five naive male Sprague-Dawley rats, maintained under conditions that were the same as those used in the first experiment, served as subjects. One week to 10 days following their arrival, they were submitted to the surgical procedure. Twenty-nine of the rats received ibotenic acid bilateral lesions of the hippocampus. The remaining 36 rats had sham operations. The rats were allowed a 2 -week period of recovery before the beginning of the experiment. The apparatus and procedure were the same as those used in the first experiment.

Histology. Twenty-five rats were accepted as having hippocampal lesions corresponding to the criteria described in Experiment 1 (see Figure 1).

Procedure. The training procedure was exactly the same as that in the first experiment. Two sham-operated and 2 hippocampuslesioned rats were eliminated because of their extended mean response latencies at the end of initial training. After the end of training, the rats remained in their home cages for a 21 -day retention interval, during which time they were never handled. The sham and lesioned rats were then divided into three groups on the basis of their training performance according to a 2 (lesion condition) $\times 3$ (cuing condition) factorial design. At the end of the retention interval, the rats in the noncued condition were placed directly into the Y-maze (Group S-NC, $n=12$; Group H-NC, $n=6$ ). The cued rats were either exposed to a series of five CSs delivered in the cuing box (Group S-BL, $n=11$; Group H-BL, $n=8$ ) or exposed to the experimental context (Group S-CTXT, $n=11$; Group H-CTXT, $n=9$ ). Then they were returned to their home cages for a 5 -min period before being tested. All the rats were then retrained for 25 consecutive trials, under conditions that were the same as those used in the initial training.

\section{Results}

Acquisition of the Y-maze task. During the 5-min period of pretraining (see Figure 5), the hippocampuslesioned rats had a significantly higher number of arm visits than did the sham-operated rats $[F(1,51)=21.08$, $p<.001]$.

During the training phase, a two-way ANOVA (lesion condition $\times$ trial block) revealed a significant main effect of trial block for each performance measure, indi- 


\section{1-day TTI}

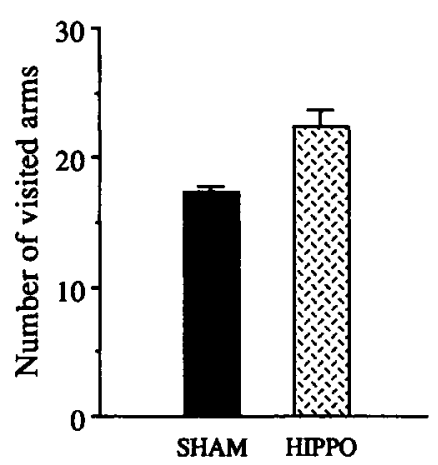

PRETRAINING

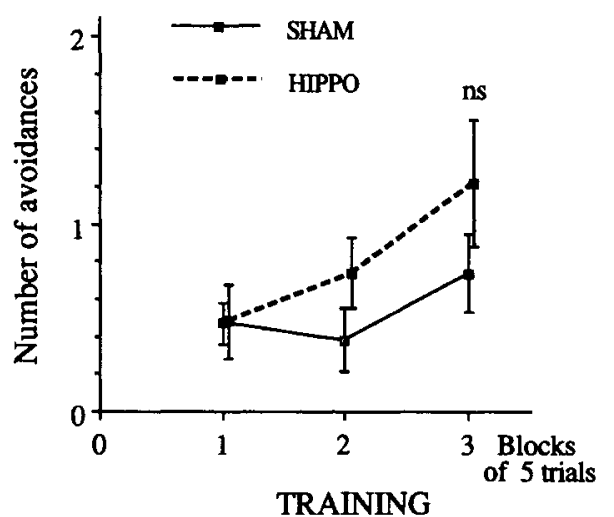

Figure 5. Twenty-one-day training-to-test interval (TTI). Mean number of arms visited ( $\pm S E M)$ for sham-operated (SHAM) and hippocampus-lesioned (HIPPO) rats during pretraining (left panel). During pretraining, HIPPO rats visited significantly more arms than did SHAM rats $(p<.001)$.

cating a significant acquisition process [response latencies, $F(2,52)=51.85, p<.001$; number of errors, $F(2,52)$ $=20.63, p<.001$; number of avoidances, $F(2,52)=$ $4.12, p<.025]$. Hippocampus-lesioned rats demonstrated shorter response latencies than did the SHAM rats $[F(1,51)=7.31, p<.01]$. Comparisons of the number of errors and of the number of avoidances did not lead to significant differences $[F(1,51)=3.88$, and $F(1,51)=$ 1.42 , respectively]. There were no significant interactions between lesion conditions and trial blocks, regardless of the variable.

Retraining. Following the 21-day retention interval, the sham and hippocampal noncued rats demonstrated a similar time course in their performance between the end of training and the beginning of retraining for each variable [response latencies, $F(1,16)=1.12$; number of errors, $F(1,16)=1.6$; number of avoidances, $F(1,16)=$ $.10]$. However, during retraining, the hippocampuslesioned rats had shorter response latencies $[F(1,16)=$ $6.52, p<.025]$ and a higher number of avoidance responses $[F(1,16)=4.49, p<.05]$. No difference was found on the number of errors.

The effects of prior cuing after a 21-day TTI are illustrated in Figure 6. Within-group comparisons of the number of avoidances indicated a significant improvement of performance between the end of training and the beginning of retraining for the two groups cued with the experimental context [Group S-CTXT, $F(1,10)=18.05$, $p<.005$; Group H-CTXT, $F(1,8)=9.55, p<.025$ ]. This effect was not observed for the groups that were noncued or cued with the CS.

A two-way ANOVA (lesion condition $\times$ cuing condition) performed on the savings in avoidance indicated no effect in the lesion condition $[F(1,51)=.005]$, a significant effect in the cuing condition $[F(2,51)=8.48, p<$ $.001]$, and no interaction between these two factors $(F<1)$. Paired comparisons indicated that the noncued groups did not significantly differ from the groups cued with the CS [Groups S-NC/S-BL, $F(1,24)=.84$; Groups $\mathrm{H}-\mathrm{NC} / \mathrm{H}-\mathrm{BL}, F(1,12=.022]$. In contrast, the noncued groups exhibited significantly less savings in avoidance than did the groups cued with the experimental context [Groups S-NC/G-CTXT, $F(1,21)=14.48, p<.005$; Groups H-NC/H-CTXT, $F(1,13)=5.08, p<.05]$. In the sham-operated rats, Group S-CTXT demonstrated a saving in avoidance larger than that of Group S-BL [Groups S-CTXT/BL, $F(1,20)=4.37, p<.05]$. The difference between the same two groups of rats did not reach an acceptable level of significance for the hippocampuslesioned rats $[F(1,15)=3.97, .10<p<.05]$.

Comparisons of the saving scores from the sham and hippocampus-lesioned rats for the same cuing condition was not significantly different $(F \mathrm{~s}<1)$.

Performance in the radial maze task. Ten to 11 weeks following the completion of the retention test in the Y-maze (i.e., approximately 4 months following the

\section{1-day TTI}
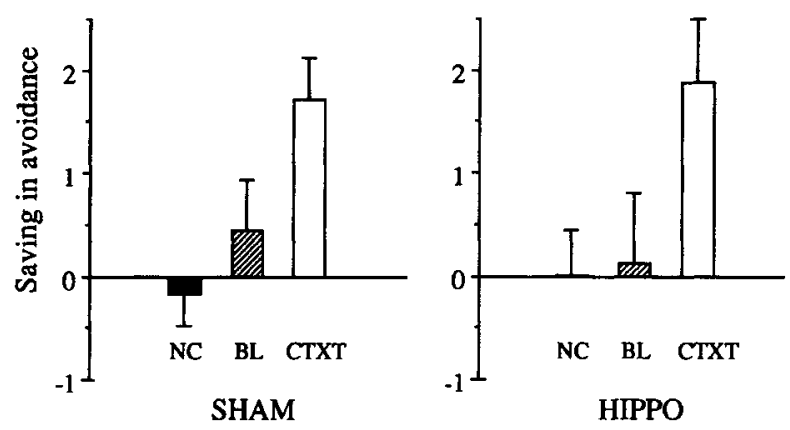

Figure 6. Twenty-one-day training-to-test interval (TTI). Mean score $( \pm S E M)$ of savings in avoidance obtained for sham-operated (SHAM) and hippocampus-lesioned (HIPPO) rats. NC, noncued; BL, cued with the CS; CTXT, cued with the context. 
hippocampal lesions), 28 sham and 18 hippocampuslesioned rats were tested in the radial maze for six consecutive days - one session per day. The results, shown in Figure 7, indicate that, throughout testing, the hippocampuslesioned rats made a greater number of reentry errors than the sham rats $[F(1,43)=52.82, p<.001]$. A significant effect of repetition during the six training sessions was obtained for the sham-operated rats $[F(5,130)=$ $3.52, p<.01]$, but not for the hippocampus-lesioned rats $[F(5,85)=.56]$.

\section{Discussion}

The results of Experiment 2 confirm the results of Experiment 1 in showing that hippocampus-lesioned rats can acquire an avoidance brightness discrimination task as well as control rats. The rats with lesions to the hippocampus were more active and had better avoidance scores than the sham rats, but their discrimination performance was similar. Moreover, retention of the task was similar for the sham and lesioned rats after a 21-day retention interval.

Experiment 2 confirms that, after a long posttraining interval, pretest exposure to the CS is no longer an effective retrieval cue, but exposure to the experimental context is a very potent retrieval cue (Gisquet-Verrier et al., 1989). Unexpectedly, the cuing procedure had identical effects in rats with damage to the hippocampus, which also showed a selective sensitivity to the contextual cues. These results demonstrate that rats with a hippocampal lesion are able to remember an experimental context and relate it to the initial training episode. They further indicate that the hippocampal formation is not necessary for the maturation (qualitative changes) of the memory trace during the retention interval, since the decrease of the CS as a retrieval cue over 21 days was observed in hippocampal as well as control rats. Finally, the results demonstrate that lesions to the hippocampus

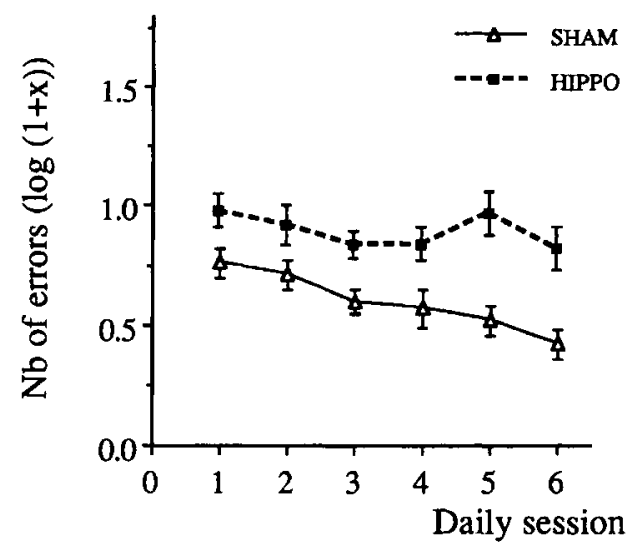

Figure 7. Mean number of errors $[\log (x+1) \pm S E M]$ obtained for sham-operated (SHAM) and hippocampus-lesioned (HIPPO) rats for visiting eight different arms in the radial maze. HIPPO rats demonstrated a significantly higher number of errors than did SHAM rats. do not prevent the retrieval processes promoted by a preexposure to the experimental context.

\section{GENERAL DISCUSSION}

The critical results from the present study can be summarized in the following way. First, selective hippocampal lesions, which disrupt the acquisition of a standard radial maze task, do not influence the acquisition or retention of an avoidance brightness discrimination task. Second, pretest exposure to the CS shortly after training, or to the experimental context a long time after training, produced an enhancement of the subsequent retention performance in hippocampal and control subjects. This latter finding shows that the integrity of the hippocampus is not required in the retrieval processes that are promoted by prior cuing, even when the retrieval cues consist of contextual cues. Each of these points will be developed and discussed in the following text.

Our results confirm the well-documented finding that hippocampal damage causes selective deficits in the acquisition of some learning tasks, but spares others (see Squire, 1987; Sutherland \& Rudy, 1989). As expected, the hippocampus-lesioned rats were severely impaired in the radial maze task; they exhibited a larger number of errors than the normal rats, with no improvement of performance during training sessions. The spatial deficit was equally severe 1 month (Experiment 1) or 4 months (Experiment 2) after the surgery, demonstrating an absence of functional recovery following ibotenic acid hippocampal lesions.

In addition to confirming the determinant role of the hippocampus in spatial learning (O'Keefe \& Nadel, 1978), the present results demonstrate that the lesions did affect the acquisition of a task requiring the integrity of the hippocampus.

In agreement with previous reports, the hippocampuslesioned rats did not show any performance disruption during the training and retraining of the avoidance brightness discrimination task. To our knowledge, the effects of hippocampal lesions on this particular task have not been studied, but no disruption of the task was expected, because the avoidance brightness discrimination is a combination of two tasks that are known to be unaffected by hippocampal lesions. Indeed, the lesioned rats demonstrated a normal discrimination performance in terms of number of errors, confirming that the simultaneous brightness discrimination is not affected by hippocampal damage (Silveria \& Kimble, 1968). The higher avoidance scores obtained during training (Experiment 1) and retraining (Experiments 1 and 2) confirmed a substantial number of findings, in which hippocampal lesions enhanced the number of avoidance responses in a two-way active avoidance task in rats (Isaacson, Douglas, \& Moore, 1961; Kimble, 1968; Olton, 1973). The fact that the rats with damage to the hippocampus visited significantly more arms of the Ymaze during the pretraining period and exhibited shorter 
response latencies over all training and retraining confirmed the well-known finding that hippocampal lesions induce hyperactivity (Means, Leander, \& Isaacson, 1971; Roberts, Dember, \& Brodwick, 1962). In summary, the results obtained with the avoidance brightness discrimination task agree with the literature and confirm that the acquisition of tasks involving consistent performance of a single response triggered by a specific sensory cue is unaffected by hippocampal lesions.

Our results also indicate that retention of the avoidance brightness discrimination task was not affected by the lesion of the hippocampal formation, regardless of the length of the retention interval. This result does not seem to agree with the existing literature, in which an acceleration in the rate of forgetting in subjects with hippocampal damage is frequently postulated. However, a careful reexamination of the studies addressing this particular problem indicates that this assertion has never been clearly demonstrated. It has been repeatedly reported that subjects with hippocampal lesions tend to forget newly acquired information faster than controls when the memory of specific events is studied over relatively short intervals (e.g., working memory; Thompson, 1981; Walker \& Means, 1973; Walker, Messer, Freund, \& Means, 1972; Winocur, 1985; Zola-Morgan \& Squire, 1985). However, in a recent work using selective ibotenic lesions, Jarrard (1993) demonstrated a normal rate of forgetting in hippocampus-lesioned rats over a 120 -sec delay that followed the sample presentation in a delayed nonmatching-to-sample task. Jarrard proposed that the increased rates of forgetting obtained in other studies could have been due to extensive lesions that were not restricted to the hippocampus proper. Only a few researchers have investigated the effects of hippocampal lesions on long-term retention of well-acquired tasks. The results are far from being fully conclusive, often demonstrating an increased sensitivity to interference rather than an accelerated rate of forgetting (Sara \& David-Remacle, 1981; Winocur 1985). The demonstration that Subject H.M. exhibited a faster rate of forgetting over long retention intervals than Korsakoff patients (Huppert \& Piercy, 1979) has even been called into question in an experiment with the same design (Freed, Corkin, \& Cohen, 1987). These data, as well as our own, suggest that when trained to a similar performance level, humans or animals with hippocampal lesions do display a normal rate of forgetting.

The effects of prior cuing fully confirm our previous results with normal rats (Gisquet-Verrier, 1992; GisquetVerrier \& Alexinsky, 1990; Gisquet et al., 1989): A pretest exposure to the CS dramatically increased retention performance when it was delivered shortly after training (i.e., 1 day), but no longer had any effect when delivered after a 21-day TTI. After such a delay, however, a pretest exposure to the experimental context largely improved the subsequent retention performance. The present experiments provide an additional demonstration of the effectiveness of these particular cues as retrieval cues and confirm that this effect is time dependent.
In contrast with what was expected, the hippocampal lesions did not affect the rats' sensitivity to prior cuing. The effects of prior cuing on the hippocampus-lesioned rats were the same as those on the sham-operated rats. This finding has three major implications. First, the retrieval processes that are promoted by prior cuing do not require the integrity of the hippocampus. Second, the hippocampus is not involved in the maturation processes of the memory trace, which is evidenced by the alteration of the cuing effectiveness over time. Third, the fact that rats with damage to the hippocampus can benefit from a pretest exposure to the experimental context indicates that they are able to take the context into account and relate it to the initial training situation. Each of these three points will be discussed separately.

\section{Retrieval Processes Promoted by Prior Cuing and the Hippocampus}

Our results indicate very clearly that the hippocampus is not involved in the retrieval processes that are promoted by retrieval cues. This is true for cues given at short or long delays after training and for "simple" or "complex" cues. The noninvolvement of the hippocampus in those retrieval processes can, however, be related to other literature that has documented the effects of retrieval cues on amnesic patients with temporal lobe damage involving hippocampal damage. There are numerous examples that show that amnesic patients can be aided by retrieval cues at the time of testing. For instance, Warrington and Weiskrantz (1974) showed that amnesic patients are able to demonstrate normal retention of verbal material by using partial information as a retrieval method (cued-recall retrieval procedure). In this method, components of the original stimulus material (the three initial letters of the target word) were presented at retention testing and served as prompts or reminders to facilitate the retrieval of memories that had apparently been lost. Together with other results, this evidence led several investigators to suggest that the amnesia associated with temporal lobe damage was due to retrieval dysfunction rather than to a storage failure. However, this interpretation, proposed by Warrington and Weiskrantz (1974), has been called into question by studies that have shown that cued-recall procedures are able to improve memory in normal subjects as well as in amnesic patients (Mayes, Mendell, \& Sow, 1981; Wood \& Piercy, 1974). This suggests that the amnesic deficit is not a mere retrieval deficit that would simply be circumvented by a partial-information procedure. Warrington and Weiskrantz (1982) then proposed that the cued-recall retrieval technique was able to induce automatic activation of a preexisting memory, and that this process was different from the conscious recollection required for free recall and recognition. In cued-recall tests (later termed repetition priming), subjects are not told to use the cues explicitly to recall a previous memory, but are simply told to say the first word that comes to mind. Enhancement of the retention performance resulting from priming does not require conscious rec- 
ollection of previously recorded information, and it has been regarded as being due to automatic reactivation involving implicit (Schacter, 1992) or nondeclarative (Squire, 1992) memory. This might explain why priming is preserved in cases of temporal amnesia in humans.

A similar evolution concerning the interpretation of the effects that are induced by prior cuing can be found in the rat literature. First, it has been shown that behavioral deficits resulting from hippocampal damage can be compensated by prior cuing. Winocur and Black (1978) demonstrated that the passive avoidance deficit of hippocampus-damaged rats can be compensated by providing reminder cues that emphasized the aversive aspect of the training experience (the electric shock itself, or a shock-related stimulus, such as a box with the characteristics of the goalbox), before the retention test. In another study, Baker, Kesner, and Michal (1981), using a one-trial passive avoidance task, showed that rats that were rendered amnesic with a bilateral electric stimulation of the hippocampus demonstrated a recovery of memory when they received a footshock reminder cue. These results have supported the interpretation that, as in humans, hippocampal lesions in rats do not actually impair storage or consolidation processes, but merely disrupt the retrieval.

Finally, the present results demonstrate that prior cuing enhances performance in normal as well as hippocampal rats. Similar to the proposals for human subjects, one may thus suggest that prior cuing induces an automatic reactivation of the initial representation.

Indeed, prior cuing in rats presents striking similarities to priming in humans:

1. Both consist of exposing the subjects to part of the initial information to be remembered.

2. In both conditions, the partial information must be the target item or must be closely associated with it.

3 . Both result in an improvement of the subsequent retention performance in the normal subject.

4. As with rats, human subjects are not required to explicitly remember a prior event, but merely to perform a task that might be considered to involve implicit memory.

5. Both are preserved following damage to the hippocampal formation.

6. Both can occur with newly associated information-that is, information associated after the hippocampal damage. In contradiction to early hypotheses, there is now a large body of evidence demonstrating that the priming effect does not require a preexisting representation. Amnesic patients, like normal subjects, demonstrate priming for novel material, such as unfamiliar visual objects (Schacter, Cooper, \& Delaney, 1990), nonwords (Haist, Musen, \& Squire, 1991), or novel line patterns (Musen \& Treisman, 1990). The present results demonstrate that, in rats, a prior-cuing effect can occur with information acquired after the hippocampal lesion.

Finally, two categories of priming have been shown in normal subjects as well as in amnesic patients. (1) Di- rect or repetitive priming reflects changes in early-stage perceptual processing systems, before any conceptual or semantic analysis, and allows an easier detection or identification of the stimulus. (2) Conceptual, or semantic, priming depends on the meaning of the stimulus and requires a semantic processing (i.e., a modification of the semantic memory) that cannot be accounted for by perceptual analysis. Our results indicate that, in the rat, prior cuing seems closer to conceptual priming than to repetitive priming, because the cue promoting retrieval is not the target item itself, but is associated with it at the time of the initial acquisition.

In summary, all these arguments strongly support the notion that prior cuing in rats is equivalent to priming in humans and involves a kind of memory (implicit memory) that is not dependent on the hippocampus. Such a finding further extends the similarities between humans and rats, which have already been pointed out by Squire (1992).

\section{Hippocampal Lesions and Maturation Processes}

The present results indicate a decrease in the effectiveness of the CS as a retrieval cue between 1 and 21 days after the initial learning session. Similar results were obtained for the control and the lesioned rats, showing that the maturation process underlying the shift in the effectiveness of a pretest exposure to the CS does not require the integrity of the hippocampus. Hence, this maturation process has to be dissociated from that evidenced by the gradients of retrograde amnesia described in monkeys and rodents (Cho et al., 1993; Sutherland, Arnold, \& Rodriguez, 1987; Winocur, 1990; ZolaMorgan \& Squire, 1990). In contrast, our results indicate that when the hippocampus is not necessary for the acquisition and long-term retention of a task, it is also not necessary for the late and qualitative maturation processes, evidenced by prior-cuing procedures. Whether or not there are different maturation processes that are supported by different memory systems is a question that needs to be studied in greater detail.

\section{Hippocampal Lesions and Contextual Cue}

The present experiments demonstrated that rats with hippocampal lesions do remember the original training context for at least 3 weeks. Thus, it can be assumed that in the absence of the hippocampus, rats are able to memorize a given context, associate this context with an adaptative behavior, and use it as a retrieval cue. Our results contradict the contextual retrieval theory proposed by Hirsh (1974), since they demonstrate that a pretest exposure to the experimental context promotes the retrieval of a previously stored memory even for hippocampus-lesioned rats. These results also appear to contradict the results of several other experiments suggesting that hippocampal lesions disrupt the processing of the contextual information. However, the role of the hippocampus in the processing of contextual information is not fully understood. The literature pro- 
vides contradictory evidence on the sensitivity of hippocampus-lesioned rats to contextual stimuli and on their capacity to use contextual information. This inconsistency may be due to the diversity in the procedures used to determine whether contextual stimuli are taken into account.

The idea that rats with damage to the hippocampus were unable to adequately process the experimental context originates from experiments investigating the effects of contextual changes on a well-established conditioned response. The results indicate that, unlike normal rats, those with damage to the hippocampus do not react to the contextual change and continue to behave as they did before the change. Irrelevant visual and tactile stimuli failed to disturb a well-established running response in hippocampus-lesioned rats that were trained in a runway (Raphaelson, Isaacson, \& Douglas, 1965; Wickelgren \& Isaacson, 1963). Similarly, irrelevant auditory stimuli introduced in a leverpressing situation controlled by visual stimuli did not modify the performance of lesioned monkeys (Douglas \& Pribram, 1966). Rabbits with hippocampal lesions trained to a classical CS response of the nictitating membrane failed to show any disruption of performance when further trained in a new experimental device (Penick \& Solomon, 1991). Changing the starting box of a maze reduced the performance of normal rats, but had no detectable effect on the behavior of rats with hippocampal lesions (Hughey \& Koppenaal, 1987). However, rather than indicating a poor memory of the experimental context for the rats with hippocampal lesions, these results might also be due to a lesion-induced change in the distractibility and exploratory responses. Indeed, rats with hippocampal lesions are very difficult to distract when engaged in a well-trained behavior (Gustavson, 1975) and they show impaired exploratory behavior in response to environmental changes. Gerbils, rats, and mice with hippocampal or parahippocampal lesions exhibited reduced exploratory responses to a novel item in a familiar environment (Glickman, Higgins, \& Isaacson, 1970; Schenk, Inglin, \& Gyger, 1982) and did not show normal time development of their response to novel stimuli (Suess \& Berlyne, 1978). Furthermore, when the environmental context is important for performing the task, such as in a radial maze task, it has been demonstrated that, in reaction to a contextual change, rats with fornix lesions exhibit a disruption of performance that is greater than that for normal rats (Maho, Villemin, \& Ammassari-Teule, 1991).

In summary, an impaired reaction to a contextual change cannot be interpreted as a convincing demonstration that subjects with hippocampal lesions are impaired in the processing of contextual cues, particularly when the context is not a relevant cue of the task.

Other experiments have provided clear evidence that rats with hippocampal lesions are able to take into account the experimental context and perform simple discriminations that are based upon contextual stimuli. For example, Good and Honey (1991) demonstrated that rats with hippocampal lesions were able to learn a Pavlovian contextual discrimination in which food was delivered in one context but not in another. In another study, rats with damage to the hippocampus were apparently able to discriminate between two mazes that contained different visual and tactile cues, since they behaved differently (turning right or turning left) in each of them (Hughey \& Koppenaal, 1987). It has also been shown that rats are able to discriminate between two arms of a radial maze (White \& McDonald, 1993) and that they demonstrate latent inhibition following preexposure to an experimental context (Honey \& Good, 1993). Finally, our results indicate that rats with damage to the hippocampus do use the experimental context in order to adequately retrieve information previously acquired in this particular context.

Moreover, some studies have suggested that rats with hippocampal lesions show even stronger conditioning to context than normal rats do. The most striking evidence for such an interpretation has been provided by Winocur, Rawlins, and Gray (1987). In their experiment, rats were submitted to a Pavlovian conditioning in which the occurrence of an electric shock could be signaled by a CS. The normal rats exhibited little conditioning to the background stimuli when the UCS was always preceded by the $\mathrm{CS}$, and conditioning to the contextual cues increased when the pairing between the CS and the UCS decreased (see also Odling-Smee, 1975). The rats with hippocampal lesions showed strong conditioning to the background, even when the UCS was always signaled by the CS. In other words, the rats with damage to the hippocampus were unable to modulate their conditioning to the contextual cues as a function of the predictive value of the CS. Opposite results were obtained by Selden, Everitt, Jarrard, and Robbins (1991), who used an experimental design close to that used by Winocur et al. (1987). However, Selden et al.'s results could have been due to a delay in the acquisition processes of rats with damage to the hippocampus, rather than to the rats' inability to process contextual information. A similar interpretation may also account for the results obtained by Phillips and LeDoux (1992), who used a freezing index in order to quantify contextual fear conditioning.

The hypothesis that hippocampus-lesioned rats form abnormally strong associations with contextual stimuli is consistent with the results from many other studies. For example, the higher sensitivity to contextual cues might explain the difficulties that hippocampally lesioned rats have in extinguishing a previously acquired behavior (Isaacson et al., 1961; Jarrard, Isaacson, \& Wickelgren, 1964). It might also account for the difficulties that rats with lesions to the hippocampus have in transferring a single discrimination problem in successively presented different contexts (Winocur \& Olds, 1978), in acquiring two different tasks in the same experimental context (Winocur \& Gilbert, 1984), or even in reversing a previously acquired discrimination (Berger \& Orr, 1983; Douglas \& Pribram, 1966; Teitel- 
baum, 1964). Nevertheless, it is worth mentioning that such an impairment could be considerably reduced by increasing the discriminability between the experimental contexts used during the original discrimination and reversal (Hughey \& Koppenaal, 1987; Winocur, 1980; Winocur \& Olds, 1978).

This short review demonstrates that, in some circumstances, rats with hippocampal lesions show an exaggerated tendency to relate the context to a particular training episode. However, rats with hippocampal lesions exhibit severe difficulties in the use of contextual information every time they have to combine contextual information with other information in order to select the behavior to be presented. For example, hippocampuslesioned rats have demonstrated severe difficulties when required to behave differently in a T-maze, depending on their motivational state (Hirsh, 1980; Hirsh, Holt, \& Mosseri, 1978). In another study, hippocampal rats were disrupted when they were required to learn that, in a given context, stimulus $x$ predicted the reinforcement, but stimulus $y$ did not, and that the reverse discrimination was required in another context (Good \& Honey, 1991). Good and Honey (1993) showed that latent inhibition demonstrated by hippocampal rats was not context dependent. This result could have been due to the fact that the hippocampal rats were unable to perform an association between the to-be-conditioned stimulus and the experimental context in which it was delivered.

These results have been interpreted as being due to the difficulties that hippocampal rats have in processing contextual information. However, the whole set of evidence presented here, including our own present results, strongly suggests that hippocampal rats are able to process, store, and retrieve contextual information. The difficulties of the hippocampal rats seem to arise when they are expected to behave according to a representation that combines contextual and other information. Accordingly, the difficulties of the hippocampal rats in these studies mainly seem to be due to their inability to use a compound stimulus, with contextual information as one element of the compound. Sutherland and Rudy (1989) have already proposed that rats with lesions to the hippocampus are unable to perform configural associations combining the representation of elementary stimulus events (that could be the context) to construct unique representations that can enter into the control of behavior. However, the literature on the role of the hippocampus in configural discriminations has provided numerous contradictory results (see Davidson, McKerman, \& Jarrard, 1993; Gallagher \& Holland, 1992; Gisquet-Verrier \& Neuenschwander-El Massioui, 1994). The main problem with the configural association theory is that it is still not yet possible to make consistent predictions (except for spatial tasks) about when a rat would solve a discrimination by the use of configural associations. A posteriori interpretations that are based upon the level of performance of hippocampal rats cannot be considered as a convincing way to determine whether or not a task can be defined as configural.
In conclusion, the present experiments provide supplementary evidence that extrahippocampal structures support acquisition, retention, and retrieval of a large amount of experience. In addition, these results demonstrate that the prior-cuing effect can be added to the numerous learning capacities that are known to be preserved following hippocampal damage (see Squire, 1992). Now there are convincing arguments to support the assumption that prior cuing in rats is equivalent to priming in man and thus could be used as a model of implicit memory in animals. A question remains, however: How many different extrahippocampal systems are responsible for all the preserved acquisition capacities following hippocampal lesions? This will be, without a doubt, one of the most exciting problems to be debated in the present decade.

\section{REFERENCES}

BaKer, L. J., Kesner, R. P., \& Michal, R. E. (1981). Differential effects of a reminder cue on amnesia induced by stimulation of amygdala and hippocampus. Journal of Comparative \& Physiological Psychology, 95, 312-321.

BERGER, T. W., \& ORR, W. B. (1983). Hippocampectomy selectively disrupts discrimination reversal learning of the rabbit nictitating membrane response. Behavioural Brain Research, 8, 49-68.

Bower, G. H. (1967). A multi-component theory of the memory trace. In J. W. Spence \& J. T. Spence (Eds.), The psychology of learning and motivation (Vol. 1). New York: Academic Press.

Cho, Y. H., Beracochea, D., \& Jaffard, R. (1993). Extended temporal gradient for retrograde and anterograde amnesia produced by ibotenate entorhinal cortex lesions in mice. Journal of Neuroscience, 13, 1759-1766.

Davidson, T. L., McKerman, M. G., \& Jarrard, L. E. (1993). Hippocampal lesions do not impair negative patterning: A challenge to configural association theory. Behavioral Neuroscience, 107, 227234.

DeVietTI, T. L., Conger, G. L., \& KirKPatrick, B. R. (1977). Comparison of the enhancement gradients of retention obtained with stimulation of the mesencephalic reticular formation after training or memory reactivation. Physiology \& Behavior, 19, 549-554.

Deweer, B., Sara, S. J., \& Hars, B. (1980). Contextual cues and memory retrieval in rats: Alleviation of forgetting by a pretest exposure to background stimuli. Animal Learning \& Behavior, 8, 265 272.

Douglas, R. J., \& Pribram, K. H. (1966). Learning and limbic lesions. Neuropsychologia, 4, 197-220.

Freed, D. M., Corkin, S., \& Cohen, N. J. (1987). Forgetting in H.M.: A second look. Neuropsychologia, 25, 461-471.

Gallagher, M., \& Holland, P. C. (1992). Preserved configural learning and spatial learning impairment in rats with hippocampal damage. Hippocampus, 2, 81-88.

GisqueT-VERRIER, P. (1992). Coherence of retrieval cues, rather than additivity, determines prior cuing effectiveness in the rat. Animal Learning \& Behavior, 20, 382-392.

Gisquet-Verrier, P., \& Alexinsky, T. (1986). Does contextual change determine long-term forgetting? Animal Learning \& Behavior, 14, 349-358.

Gisquet-VerRier, P., \& Alexinsky, T. (1987). Time-dependent modification of the memory trace evidenced by pretest cuing in rats. Society for Neuroscience Abstracts, 13, 1316.

Gisquet-VerRier, P., \& Alexinsky, T. (1988). Time-dependent fluctuations of retention performance in an aversively motivated task. Animal Learning \& Behavior, 16, 58-66.

Gisquet-VerRier, P., \& AleXINSKY, T. (1990). Facilitative effect of a pretest exposure to the CS: Analysis and implications for the memory trace. Animal Learning \& Behavior, 18, 323-331.

Gisquet-Verrier, P., DeKeYNe, A., \& AlEXINSKy, T. (1989), Differ- 
ential effects of several retrieval cues over time: Evidence for timedependent reorganization of memory. Animal Learning \& Behavior, 17, 394-408.

Gisquet-Verrier, P., \& Neuenschwander-ElMassioui, N. (1994). Selective hippocampal lesions in rats affect retention and acquisition of a positive patterning discrimination. Manuscript submitted for publication.

Glickman, S. E., Higgins, T. J., \& Isaacson, R. L. (1970). Some effects of hippocampal lesions on the behavior of Mongolian gerbils. Physiology \& Behavior, 5, 931-938.

Good, M., \& Honey, R. C. (1991). Conditioning and contextual retrieval in hippocampal rats. Behavioral Neuroscience, 105, 499-509.

GoOD, M., \& Honey, R. C. (1993). Selective hippocampal lesions abolish the contextual specificity of latent inhibition and conditioning. Behavioral Neuroscience, 107, 23-33.

GORDON, W. C., \& SPEAR, N. E. (1973). The effects of strychnine on recently acquired and reactivated passive avoidance memories. Physiology \& Behavior, 10, 1071-1075.

Gustavson, J. W. (1975). Distractibility and reactivity under different response conditions following hippocampal lesions in rats. Behavioral Biology, 15, 479-484.

HaIST, F., MUSEN, G., \& SQUiRe, L. R. (1991). Intact priming of words and nonwords in amnesia. Psychobiology, 19, 275-285.

HIRSH, R. (1974). The hippocampus and contextual retrieval of information from memory: A theory. Behavioral Biology, 12, 421-444.

HIRSH, R. (1980). The hippocampus, conditional operations, and cognition. Physiological Psychology, 8, 175-182.

Hirsh, R., Holt, L., \& Mosseri, A. (1978). Hippocampal mossy fibers, motivational states, and contextual retrieval. Experimental Neurology, 62, 68-79.

Honey, R. C., \& Good, M. (1993). Selective hippocampal lesions abolish the contextual specificity of latent inhibition and conditioning. Behavioral Neuroscience, 107, 23-33.

Howard, R. L., GLendenning, R. L., \& MEYER, D. R. (1974). Motivational control of retrograde amnesia: Further explorations and effects. Journal of Comparative \& Physiological Psychology, 86, 187-192.

Hughey, D. J., \& KoppenaAl, R. J. (1987). Hippocampal lesions in rats alter learning about intramaze cues. Behavioral Neuroscience, 101, 634-643.

HupPeRT, F. A., \& Piercy, M. (1979). Normal and abnormal forgetting in organic amnesia: Effect of locus of lesion. Cortex, 15, 385-390.

IsaAcson, R. L., Douglas, R. J., \& MoORE, R. Y. (1961). The effect of radical hippocampal ablation on acquisition of avoidance responses. Journal of Comparative \& Physiological Psychology, 54, 625-628.

JARRARD, L. E. (1989). On the use of ibotenic acid to lesion selectively different components of the hippocampal formation. Journal of Neuroscience Methods, 29, 251-259.

JARRARD, L. E. (1993). On the role of the hippocampus in learning and memory in the rat. Behavioral \& Neural Biology, 60, 9-26.

JARRARD, L. E., ISAACSON, R. L., \& WICKELGREN, W. O. (1964). Effects of hippocampal ablation and intertrial interval on runway acquisition and extinction. Journal of Comparative \& Physiological Psychology, 57, 442-444.

KIMBLE, D. P. (1968). Hippocampus and internal inhibition. Psychological Bulletin, 70, 285-295.

KLEIN, S. B., \& SPEAR, N. E. (1970). Reactivation of avoidance-learning memory in the rat after intermediate retention interval. Journal of Comparative \& Physiological Psychology, 72, 498-504.

KoppenaAl, R., J., Jagoda, E., \& CRUCE, J. A. F. (1967). Recovery from ECS-produced amnesia following a reminder. Psychonomic Science, 9, 293-294.

LEwIS, D. J. (1979). Psychobiology of active and inactive memory. Psychological Bulletin, 86, 1054-1083.

Maho, C., Villemin, E., \& Ammassari-Teule, M. (1991). Limited and extensive cuing inversely control spatial learning performance in fornix-damaged and nonlesioned rats. Psychobiology, 19, 323-331.

MAYES, A., MeNDELL, P., \& Sow, S. (1981). Further similarities between amnesia and normal attenuated memory: Effects with paired-associate learning and contextual shifts. Neuropsychologia, 18, 655-664.
Means, L. W., Leander, J. D., \& Isaacson, R. L. (1971). The effects of hippocampectomy on alternation behavior. Physiology \& Behavior, 6, 17-22.

Miller, R. R., Kasprow, W. J., \& Schatman, T. R. (1986). Retrieval variability: Sources and consequences. American Journal of Psychology, 99, 145-218.

Miller, R. R., \& SPRINGER, A. D. (1972). Induced recovery of memory in rats following electroconvulsive shock. Physiology \& Behavior, 8, 645-651.

Misanin, J. R., Miller, R. R., \& Lewis, D. J. (1968). Retrograde amnesia produced by electroconvulsive shock after reactivation of a consolidated memory trace. Science, $160,554-555$.

Moscovitch, M. (1992). Memory and working-with-memory: A component process model based on modules and central systems. Journal of Cognitive Neuroscience, 4, 257-267.

Musen, G., \& Treisman, A. (1990). Implicit and explicit memory for visual patterns. Journal of Experimental Psychology: Learning, Memory, \& Cognition, 16, 127-137.

Oding-SmeE, F. J. (1975). The role of background stimuli during Pavlovian conditioning. Quarterly Journal of Experimental Psychology, 27, 161-169.

O'KeEfE, J., \& NADEL, L. (1978). The hippocampus as a cognitive map. Oxford: Oxford University Press, Clarendon Press.

OLToN, D. S. (1973). Shock-motivated avoidance and the analysis of behavior. Psychological Bulletin, 79, 243-251.

PAXINos, G., \& WATSON, C. (1986). The rat brain in stereotaxic coordinates. New York: Academic Press.

Penick, S., \& Solomon, P. R. (1991). Hippocampus, context and conditioning. Behavioral Neuroscience, 105, 611-617.

PhILlips, R. G., \& LeDoux, J. E. (1992). Differential contribution of amygdala and hippocampus to cued and contextual fear conditioning. Behavioral Neuroscience, 106, 274-285.

Raphelson, A. C., IsAacson, R. L., \& Douglas, R. J. (1965). The effect of distracting stimuli on the runway performance of limbic damaged rats. Psychonomic Science, 3, 483-484.

Roberts, W. W., Dember, W. N., \& Brodwick, M. (1962). Alternation and exploration in rats with hippocampal lesions. Journal of Comparative \& Physiological Psychology, 55, 695-700.

Rouanet, H., Bernard, J. H., \& Leroux, B. (1990). Statistiques en sciences humaines: Analyse inductive des données. Paris: Dunod.

Sara, S. J. (1973). Progressive development of avoidance response after training, ECS, and repeated testing. Bulletin of the Psychonomic Society, 2, 134-136.

SARA, S. J., \& DAVID-REMACLE, M. (1981). Discriminative avoidance learning in hippocampal and cortical rats: Acquisition rate, behavioral strategies, and long-term retention. Physiological Psychology, 9, 37-48.

SChaCTER, D. L. (1992). Priming and multiple memory systems: Perceptual mechanisms of implicit memory. Journal of Cognitive Neuroscience, 4, 244-256.

SChaCter, D. L., CoOper, L. A., \& Delaney, S. M. (1990). Implicit memory for unfamiliar objects depends on access to structural descriptions. Journal of Experimental Psychology: General, 119, 5-24.

SCHENK, F., INGLIN, F., \& GYGER, M. (1982). Activity and exploratory behavior after lesions of the medial entorhinal cortex in the woodmouse. Behavioral \& Neural Biology, 37, 89-107.

Selden, N. R. W., Everitt, B. J., JaRRARD, L. E., \& Robbins, T. W. (1991). Complementary roles for the amygdala and hippocampus in aversive conditioning to explicit and contextual cues. Neuroscience, 42, 335-350.

SiLVERIA, J. M., \& KIMBLE, D. P. (1968). Brightness discrimination and reversal in hippocampally lesioned rats. Physiology \& Behavior, 3 , 625-630.

SPEAR, N. E. (1978). The processing in memories: Forgetting and retention. Hillsdale, $\mathrm{NJ}$ : Erlbaum.

SPRINGER, A. D., \& MilLER R. R. (1972). Retrieval failure induced by electroconvulsive shock: Reversal with dissimilar training and recovery agents. Science, 177, 628-630.

SQUIRE, L. R. (1987). Memory and brain. New York: Oxford University Press, Clarendon Press.

SQUTRE, L. R. (1992). Memory and the hippocampus: A synthesis from 
findings with rats, monkeys, and humans. Psychological Review, 99, 195-231.

SUESS, W. M., \& BERLYNE, D. E. (1978). Exploratory behavior as a function of hippocampal damage, stimulus complexity and stimulus novelty in the hooded rat. Behavioral Biology, 23, 487-499.

Sutherland, R. J., ARnold, K. A., \& Rodriguez, A. R. (1987). Anterograde and retrograde effects on place memory after limbic or diencephalic damage. Society for Neuroscience Abstracts, 13, 1066.

Sutherland, R. J., \& RUDY, J. W. (1989). Configural association theory: The role of the hippocampal formation in learning, memory, and amnesia. Psychobiology, 17, 129-144.

Teitelbaum, H. (1964). A comparison of the effects of orbitofrontal and hippocampal lesions upon discrimination learning and reversal in the cat. Experimental Neurology, 9, 452-462.

TEyleR, T. J., \& DiScenNa, P. (1986). The hippocampal memory indexing theory. Behavioral Neuroscience, 100, 147-157.

Thompson, R. (1981). Rapid forgetting of a spatial habit in rats with hippocampal lesions. Science, 212, 959-960.

Underwoon, B. J. (1969). Attributes of memory. Psychological Review, 67, 73-95.

WALKER, D. W., \& MEANS, L. W. (1973). Single alternation performance in rats with hippocampal lesions: Disruption by an irrelevant task interposed during the intertrial interval. Behavioral Biology, 9, 93-104.

Walker, D. W., Messer, L. G., Freund, G., \& Means, L. W. (1972). Effect of hippocampal lesions and intertrial interval on singlealternation performance in the rat. Journal of Comparative \& Physiological Psychology, 80, 469-477.

WARRINGTON, E. K., \& WEISKRANTZ, L. (1974). The effects of prior learning on subsequent retention in amnesic patients. Neuropsychologia, 12, 419-428.

Warrington, E. K., \& Weiskrantz, L. (1982). Amnesia: A disconnection syndrome? Neuropsychologia, 20, 233-248.

White, N. M., \& MCDonald, R. J. (1993). Acquisition of a spatial conditioned place preference is impaired by amygdala lesions and improved by fornix lesions. Behavioural Brain Research, 55, 269281

Wickelgren, W. O., \& Isaacson, R. L. (1963). Effect of the introduction of irrelevent stimulus upon runway performance of the hippocampectomized rat. Nature, 200, 48-50.

Winocur, G. (1980). The hippocampus and cue utilization. Physiological Psychology, 8, 280-288.

WinOCUR, G. (1985). The hippocampus and thalamus: Their role in short- and long-term memory and the effects of interference. Behavioural Brain Research, 16, 135-152.

WiNOCUR, G. (1990). Anterograde and retrograde amnesia in rats with dorsal hippocampal or dorsomedial thalamic lesions. Behavioural Brain Research, 38, 145-154.

Winocur, G., \& BLACK, A. H. (1978). Cue-induced recall of a passive avoidance response by rats with hippocampal lesions. Physiology \& Behavior, 21, 39-44.

Winocur, G., \& Gilbert, M. (1984). The hippocampus, context, and information processing. Behavioral \& Neural Biology, 40, 27-43.

WinOCUR, G., \& OLDS, J. (1978). Effects of context manipulation on memory and reversal learning in rats with hippocampal lesions. Journal of Comparative \& Physiological Psychology, 92, 312-321.

Winocur, G., Rawlins, J. N. P., \& GraY, J. A. (1987). The hippocampus and conditioning to contextual cues. Behavioral Neuroscience, 101, 617-627.

WoOD, R. T., \& Piercy, M. A. (1974). A similarity between amnesic memory and normal forgetting. Neuropsychologia, 12, 437-445.

Zola-Morgan, S. M., \& Squire, L. R. (1985). Medial temporal lesions in monkeys impair memory in a variety of tasks sensitive to human amnesia. Behavioral Neuroscience, 99, 22-34.

Zola-Morgan, S. M., \& SQuire, L. R. (1990). The primate hippocampal formation: Evidence for a time-limited role in memory storage. Science, 250, 288-290.

(Manuscript received November 16, 1993; revision accepted for publication June 7,1994 .) 